\title{
Incidence and Characteristics of Thyroid Dysfunction Following Interferon Therapy in Patients with Chronic Hepatitis C
}

\author{
Masahiro Amenomori, Toru Mori*, Yoshihiro Fukuda, Hideo Sugawa*, Naoshi Nishida, \\ Motonobu Furukawa, Ryuichi Kita, Takehiro Sando, Toshiki Komeda and Kazuwa NaKao
}

Thyroid functions were analyzed before, during and after interferon (IFN) therapy in patients with chronic hepatitis $C$. According to the results of routine thyroid function tests and measurements of the levels of anti-thyroid autoantibody prior to the therapy, patients were divided into 2 groups; Group A (19 patients) had at least one abnormal finding related to the thyroid, and Group $B$ ( 40 patients) did not show any abnormality. Five patients (26\%) in Group A and $4(10 \%)$ in Group B showed thyroid dysfunctions which were very clearly reflected by thyrotropin (TSH) measurements. Interestingly, the time of peak TSH elevation in Group $\mathrm{A}$ (mean $\pm \mathrm{SD}, 4.3 \pm 0.8$ months) was significantly earlier than that in Group B $(6.8 \pm 0.8)$. Most patients in Group B were diagnosed as having destructive thyroiditis. These findings may suggest that the pathogenesis of IFN-induced thyroid dysfunction consists not only of exacerbation of pre-existing thyroid autoimmunity but also of de novo destructive changes even in the intact thyroid before IFN therapy.

(Internal Medicine 37: 246-252, 1998)

Key words: destructive thyroiditis, interferon-induced thyroid dysfunction, cytokine, autoimmune thyroid disorder

\section{Introduction}

Interferon (IFN) is currently used widely due to its beneficial effects in patients with chronic hepatitis $\mathrm{C}$, even though multiple reactions can occur (1). Early adverse effects are common but are not usually serious, while late effects are less common but may be difficult to detect and manage. IFN-induced thyroid dysfunction is such an adverse effect which is not infrequently encountered.

IFN-induced thyroid dysfunction has been reported to occur during the treatment not only of malignancies $(2,3)$ but also of chronic viral hepatitis. Schultz et al (4) first reported IFNinduced thyroid dysfunction in hepatitis patients, and Mayet et al (5) reported IFN-induced anti-thyroid autoantibody production or elevation of the titer of such antibodies. While there are some excellent analyses $(6,7)$, the characteristics of thyroid dysfunction have not been clearly documented in most reports $(1,4)$. In most studies it was not considered whether thyrotoxicosis occurring during IFN therapy is due to Graves' disease or to the thyrotoxic phase of destructive thyroiditis. IFN-induced Graves' disease has rarely been reported in patients without a past history or overt disease of the thyroid $(8,9)$. The pathogenesis of IFN-induced thyroid dysfunction has been reported to be due to the exacerbation of pre-existing thyroid autoimmunity (10), while some cases negative for anti-thyroid autoantibodies are also known (8).

In this study, we analyzed thyroid functions before, during and after IFN therapy in patients with chronic hepatitis C. Through classification of the patients in relation to the thyroid states prior to the IFN therapy and serial observations of thyroid function, we were able to characterize the thyroid dysfunction induced by IFN therapy in detail.

\section{Method}

\section{Patients}

We studied fifty-nine patients with histologically confirmed chronic active viral hepatitis who were positive for anti-hepa-

From the Department of Medicine and Clinical Science, Kyoto University Graduate School of Medicine and *the Department of Laboratory Medicine, Faculty of Medicine, Kyoto University, Kyoto

Received for publication May 6, 1997; Accepted for publication October 17, 1997

Reprint requests should be addressed to Dr. Masahiro Amenomori, the Department of Medicine and Clinical Science, Kyoto University Graduate School of Medicine, 54 Shougoinkawahara-cho, Sakyo-ku, Kyoto 606-8397 
titis $\mathrm{C}$ virus (HCV) antibody as determined using passive hemagglutination kits (Dinabot, Tokyo). None of the patients had noticeable goiter. Before therapy, the patients were classified into two groups; those with (Group A) and those without (Group B) at least one abnormal thyroid finding in following routine thyroid function tests to determine the serum triiodothyronine $\left(\mathrm{T}_{3}\right)$, free thyroxine $\left(\mathrm{fT}_{4}\right)$, thyrotropin $(\mathrm{TSH})$, anti-thyroid microsomal antibody (MCHA) and anti-thyroglobulin antibody (TGHA). The nineteen patients in Group A [Table 1] consisted of 9 males and 10 females (mean age, 52.5 years; range, 22-71 years). Patients 1-3 were positive for anti-thyroid autoantibodies, and Patients 1 and 2 also exhibited low levels of $\mathrm{fT}_{4}$. Patients 4-11 exhibited TSH elevation but were negative for autoantibodies: among these patients, Patients 6, 10 and 11 exhibited low $\mathrm{fT}_{4}$. However, there were 8 other patients exhibiting somewhat less marked abnormalities: Patients 12 and 13 exhibited a low level of $\mathrm{T}_{3}$, normal levels of $\mathrm{fT}_{4}$ and $\mathrm{TSH}$ and were negative for autoantibodies; Patient 14 exhibited a low level of $\mathrm{fT}_{4}$, normal levels of $\mathrm{T}_{3}$ and $\mathrm{TSH}$ and was negative for autoantibodies; Patient 15 exhibited normal thyroid function under replacement therapy after thyroidectomy for thyroid cancer; and Patients 16-19 exhibited a high level of $\mathrm{T}_{3}$, normal levels of $\mathrm{fT}_{4}$ and TSH and were negative for autoantibodies, but their thyroxine binding globulin (TBG) level was slightly elevated (mean, $36.3 \mu \mathrm{g} / \mathrm{ml}$; range, $34.1-41.1 \mu \mathrm{g} / \mathrm{ml}$ ).

The mean \pm SD for each test result for each of these subgroups in Group A is shown in Table 2, together with the mean values of 40 patients in Group B, who consisted of 25 males and 15 females (mean age, 50.5 years; range, 20-73 years).

\section{Therapy protocols}

All of the patients were administered IFN by subcutaneous or intravenous injection. Natural IFN $\alpha$ (Sumitomo, Osaka), recombinant IFN $\alpha 2 a$ (Takeda, Osaka, Nippon Roche, Tokyo), recombinant IFN $\alpha 2 b$ (Yamanouchi, Tokyo) or natural IFN $\beta$ (Daiichi, Tokyo) was used. Two therapy protocol patterns were used: T-I protocol, IFN was administered everyday for the first two weeks and three times a week for the rest of the therapy period; T-II protocol, IFN was administered three times a week throughout the therapy period. Their doses were 3-10 million units per time.

Among Group A, 6 patients were administered natural IFN $\alpha, 5$ recombinant IFN $\alpha 2 \mathrm{a}$ and 4 each recombinant IFN $\alpha 2 \mathrm{~b}$ and natural IFN $\beta$ for $4-6$ (mean, 5.8) months. T-I and T-II protocols were used for 12 and 7 patients, respectively. Among Group B, 10, 15, 12 and 3 patients were administered natural IFN $\alpha$, recombinant IFN $\alpha 2 a$, recombinant IFN $\alpha 2 b$ and natural IFN $\beta$ for 4-6 (mean, 5.7) months, respectively. The TI and TII protocols were used for 34 and 6 patients, respectively.

\section{Thyroid function and serological studies}

Serum $\mathrm{T}_{3}$ and $\mathrm{fT}_{4}$ levels were measured by radioimmunoassay ( $\mathrm{T}_{3}$ RIA BEADS, Dinabot, Tokyo and Amerlex, Amersham, Tokyo). Serum TSH was measured using an

Table 1. Laboratory Data in Group A Patients before IFN Therapy

\begin{tabular}{|c|c|c|c|c|c|c|c|c|}
\hline $\begin{array}{l}\text { Patient } \\
\text { normal }\end{array}$ & Age & Sex & 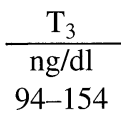 & $\begin{array}{c}\text { TBG } \\
\mu \mathrm{g} / \mathrm{ml} \\
12-30\end{array}$ & $\begin{array}{c}\mathrm{fT}_{4} \\
\mathrm{ng} / \mathrm{dl} \\
0.99-1.92\end{array}$ & $\frac{\mathrm{TSH}}{\mu \mathrm{U} / \mathrm{ml}}$ & $\begin{array}{c}\mathrm{MCHA} \\
(-)\end{array}$ & $\begin{array}{c}\text { TGHA } \\
(-)\end{array}$ \\
\hline 1 & 53 & $\mathrm{~F}$ & 147 & & 0.62 & 3.80 & 6,400 & 400 \\
\hline 2 & 44 & $\mathrm{~F}$ & 102 & & 0.86 & 2.70 & 400 & 100 \\
\hline 3 & 55 & $\mathrm{M}$ & 141 & & 1.24 & 0.92 & 400 & 400 \\
\hline 4 & 62 & $\mathrm{M}$ & 126 & & 1.09 & 10.2 & $(-)$ & $(-)$ \\
\hline 5 & 60 & $\mathrm{~F}$ & 105 & & 0.99 & 10.0 & $(-)$ & $(-)$ \\
\hline 6 & 69 & $\mathrm{~F}$ & 132 & & 0.95 & $7: 90$ & $(-)$ & $(-)$ \\
\hline 7 & 45 & $\mathrm{~F}$ & 147 & & 1.27 & 6.00 & $(-)$ & $(-)$ \\
\hline 8 & 57 & $\mathrm{~F}$ & 146 & & 1.23 & 5.40 & $(-)$ & $(-)$ \\
\hline 9 & 50 & $\mathrm{M}$ & 143 & & 1.17 & 5.20 & $(-)$ & $(-)$ \\
\hline 10 & 58 & $\mathrm{~F}$ & 155 & & 0.91 & 4.92 & $(-)$ & $(-)$ \\
\hline 11 & 59 & $\mathrm{~F}$ & 153 & & 0.90 & 4.78 & $(-)$ & $(-)$ \\
\hline 12 & 50 & M & 67 & & 2.01 & 1.60 & $(-)$ & $(-)$ \\
\hline 13 & 22 & $\mathrm{~F}$ & 82 & & 1.21 & 1.50 & $(-)$ & $(-)$ \\
\hline 14 & 57 & M & 104 & & 0.68 & 2.70 & $(-)$ & $(-)$ \\
\hline 15 & 71 & $\mathrm{~F}$ & 114 & & 1.47 & 1.70 & $(-)$ & $(-)$ \\
\hline 16 & 53 & $\mathrm{M}$ & 166 & 34.1 & 1.22 & 0.94 & $(-)$ & $(-)$ \\
\hline 17 & 45 & $\mathrm{M}$ & 178 & 41.1 & 1.63 & 1.60 & $(-)$ & $(-)$ \\
\hline 18 & 29 & $\mathrm{M}$ & 188 & 34.1 & 1.70 & 0.57 & $(-)$ & $(-)$ \\
\hline 19 & 58 & $\mathrm{M}$ & 186 & 36 & 0.99 & 0.56 & $(-)$ & $(-)$ \\
\hline
\end{tabular}

$\mathrm{T}_{3}$ : triiodothyronine, TBG: thyroxine binding globulin, $\mathrm{fT}_{4}$ : free thyroxine, $\mathrm{TSH}$ : thyrotropin, $\mathrm{MCHA}$ : anti-thyroid microsomal antibody, TGHA: anti-thyroglobulin antibody. 
AMENomori et al

Table 2. Average Values of Each Thyroid Function Test in Group A (by Subgroup) and Group B

\begin{tabular}{|c|c|c|c|c|c|c|c|c|}
\hline $\begin{array}{l}\text { Group } \\
\text { normal }\end{array}$ & Subgroup & No $(\mathrm{M} / \mathrm{F})$ & Age & $\begin{array}{c}\mathrm{T}_{3} \\
\mathrm{ng} / \mathrm{dl} \\
94-154\end{array}$ & $\begin{array}{c}\mathrm{fT}_{4} \\
\mathrm{ng} / \mathrm{dl} \\
0.99-1.92\end{array}$ & 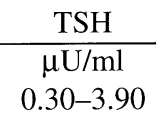 & $\begin{array}{c}\text { MCHA } \\
(-)\end{array}$ & $\begin{array}{c}\text { TGHA } \\
\text { (-) }\end{array}$ \\
\hline \multirow[t]{7}{*}{ A } & antibody (+) & $3(1 / 2)$ & $50.7 \pm 4.8$ & $124 \pm 16$ & $0.91 \pm 0.25$ & $2.07 \pm 0.82$ & $400 \sim 6,400$ & $100 \sim 400$ \\
\hline & high TSH & $8(2 / 6)$ & $57.5 \pm 6.8$ & $138 \pm 16$ & $1.06 \pm 0.14$ & $6.80 \pm 2.11$ & $(-)$ & $(-)$ \\
\hline & low $\mathrm{T}_{3}$ & $2(1 / 1)$ & $36 \pm 14$ & $74.5 \pm 7.5$ & $1.61 \pm 0.40$ & $1.55 \pm 0.05$ & $(-)$ & $(-)$ \\
\hline & low $\mathrm{fT}_{4}$ & $6(5 / 1)$ & $56.7 \pm 7.5$ & $132 \pm 24$ & $0.82 \pm 0.14$ & $4.47 \pm 1.94$ & $(-) \sim 6,400$ & $(-) \sim 400$ \\
\hline & $\begin{array}{c}\text { replacement } \\
\text { therapy }\end{array}$ & $1(0 / 1)$ & 71 & 114 & 1.47 & 1.7 & $(-)$ & $(-)$ \\
\hline & $\operatorname{high} \mathrm{T}_{3}$ & $4(4 / 0)$ & $46.3 \pm 11.0$ & $178 \pm 7.2$ & $1.39 \pm 0.29$ & $0.92 \pm 0.42$ & $(-)$ & $(-)$ \\
\hline & $\begin{array}{c}\text { Total } \\
\text { (range) }\end{array}$ & $19(9 / 10)$ & $\begin{array}{c}52.5 \pm 11.7 \\
(22-71)\end{array}$ & $\begin{array}{l}136 \pm 33 \\
(67-188)\end{array}$ & $\begin{array}{l}1.17 \pm 0.34 \\
(0.62-2.01)\end{array}$ & $\begin{array}{l}3.84 \pm 2.96 \\
(0.56-10.2)\end{array}$ & & \\
\hline B & $\begin{array}{c}\text { Total } \\
\text { (range) }\end{array}$ & $40(25 / 15)$ & $\begin{array}{c}50.5 \pm 12.8 \\
(28-73)\end{array}$ & $\begin{array}{l}127 \pm 14 \\
(99-151)\end{array}$ & $\begin{array}{l}1.15 \pm 0.16 \\
(0.99-1.39)\end{array}$ & $\begin{array}{c}1.66 \pm 0.78 \\
(0.51-3.40)\end{array}$ & $(-)$ & $(-)$ \\
\hline
\end{tabular}

Data represent the mean $\pm \mathrm{SD}$. $\mathrm{T}_{3}$ : triiodothyronine, $\mathrm{fT}_{4}$ : free thyroxine, $\mathrm{TSH}$ : thyrotropin, $\mathrm{MCHA}$ : anti-thyroid microsomal antibody, TGHA: anti-thyroglobulin antibody.

immunoradiometric assay method (TSH-IRMA, Behringwerk, Marburg). Autoantibodies, i.e. MCHA and TGHA, were quantitated using passive agglutination kits (Fujirebio, Tokyo). All measurements were performed before therapy and once every two months during and after treatment. For some patients, TSH binding inhibitor immunoglobulin (TBII) was determined using a radioreceptor assay kit (Cosmic, Tokyo), and thyroid stimulating antibody (TSAb) was determined by the increase in cAMP production from FRTL-5 cells in culture (11). For patients with high $\mathrm{T}_{3}$ levels, TBG concentration was measured by radioimmunoassay diagnostic TBG kit (Behringwerk, Marburg). The normal range for each assay was as follows: $\mathrm{T}_{3}$, 94-154 ng/dl; fT $4,0.99-1.92 \mathrm{ng} / \mathrm{dl} ; \mathrm{TSH}, 0.30-3.90 \mu \mathrm{U} / \mathrm{ml}$; MCHA and TGHA, $<100$; TBII, $<10 \%$; TSAb, $<150 \%$; and TBG, $12-30 \mu \mathrm{g} / \mathrm{ml}$.

\section{Results}

In Group A, alteration of thyroid function was observed for 5 patients (26.3\%) [Table 3], but they had no clinical symptoms. There were 3 patients (Patients 1-3) positive for thyroid autoantibodies before therapy. In two of them the titer increased during therapy (data not shown). Patient 1 exhibited hypothyroidism during therapy. High TSH levels before therapy were noted in Patients 4-11. Patients 4, 5 and 10 exhibited further increases of TSH with reciprocal $\mathrm{fT}_{4}$ decreases: these patients exhibited subclinical hypothyroidism. Each peak level of TSH is shown in Table 3 and each alteration is shown in Fig. 1. Their IFN protocols were not stopped regardless of the occurrence of thyroid dysfunction. The TSH levels of the 5 remaining patients in this subgroup decreased or remained unchanged during therapy, and no changes in the $\mathrm{fT}_{4}$ level were observed. In 3 patients with low levels of $\mathrm{T}_{3}$ or $\mathrm{fT}_{4}$ and one on replacement therapy after thyroidectomy, thyroid functions remained normal during and after IFN therapy. Of the patients with high $\mathrm{T}_{3}$ levels, Patient 16 exhibited subclinical hyperthyroidism. The thyroid functions of the other three patients in this subgroup did not change during and after therapy. TBII was measured in the patients exhibiting TSH alteration. Patient 1 and Patient 16 showed elevation of TBII.

Except for the persistent borderline hyperthyroidism in Patient 16, all abnormal thyroid function values returned to normal or pre-treatment levels within 12 months of the start of the observation period. Regarding autoantibodies in Patients 4 19, only Patient 10 exhibited a transient low titer of MCHA at 6 months during the therapy.

\section{Patient 1}

A 53-year-old female patient presented a slightly low $\mathrm{fT}_{4}$ level and was positive for anti-thyroid autoantibodies before therapy. She was administered recombinant IFN $\alpha 2 b$ at a dose of 6 million units (protocol: T-II) and complained of easy fatiguability during the 4 months of therapy. This was thought to be a common adverse effect during the IFN therapy, but her data revealed hypothyroidism (further decrease in $\mathrm{fT}_{4}$ level, a high TSH level and a slight increase in TGHA titer). These data gradually returned to normal and IFN therapy was continued for 6 months. At the 6th month, her thyroid hormone levels were 
Interferon-Induced Thyroid Dysfunction

Table 3. Development of Thyroid Dysfunction in 5 Patients of Group A

\begin{tabular}{|c|c|c|c|c|c|c|c|c|c|c|c|c|}
\hline $\begin{array}{l}\text { Patient } \\
\text { normal }\end{array}$ & Subgroup & Age/Sex & species & $\begin{array}{l}\text { IFN } \\
\text { dose (MU) }\end{array}$ & & 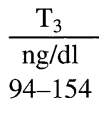 & $\begin{array}{c}\mathrm{fT}_{4} \\
\mathrm{ng} / \mathrm{dl} \\
0.99-1.92\end{array}$ & 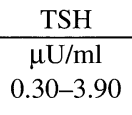 & $\frac{\text { MCHA }}{(-)}$ & $\begin{array}{c}\text { TGHA } \\
(-)\end{array}$ & $\begin{array}{c}\text { TBII } \\
\% \\
<10\end{array}$ & Diagnosis \\
\hline 5 & $\mathrm{TSH} \uparrow$ & $57 / \mathrm{F}$ & $\beta$ & 6 & $\begin{array}{l}\text { before treatment } \\
5 \text { months after }\end{array}$ & $\begin{array}{l}105 \\
115\end{array}$ & $\begin{array}{l}0.99 \\
0.71\end{array}$ & $\begin{array}{l}10.0 \\
17.0\end{array}$ & $\begin{array}{l}(-) \\
(-)\end{array}$ & $\begin{array}{l}(-) \\
(-)\end{array}$ & $\begin{array}{c}(-) \\
-15.3\end{array}$ & hypothyroidism \\
\hline 10 & $\mathrm{TSH} \uparrow$ & $58 / \mathrm{F}$ & $\alpha 2 b$ & 6 & $\begin{array}{l}\text { before treatment } \\
4 \text { months after }\end{array}$ & $\begin{array}{l}155 \\
141\end{array}$ & $\begin{array}{l}0.91 \\
0.53\end{array}$ & $\begin{array}{l}4.92 \\
12.8\end{array}$ & $\begin{array}{l}(-) \\
(-)\end{array}$ & $\begin{array}{l}(-) \\
(-)\end{array}$ & $\begin{array}{l}(-) \\
(-)\end{array}$ & hypothyroidism \\
\hline
\end{tabular}

IFN: dose (MU: million units per time). $\mathrm{T}_{3}$ : triiodothyronine, $\mathrm{fT}_{4}$ : free thyroxine, $\mathrm{TSH}$ : thyrotropin, MCHA: anti-thyroid microsomal antibody, TGHA: anti-thyroglobulin antibody, TBII: thyrotropin binding inhibitor immunoglobulin.

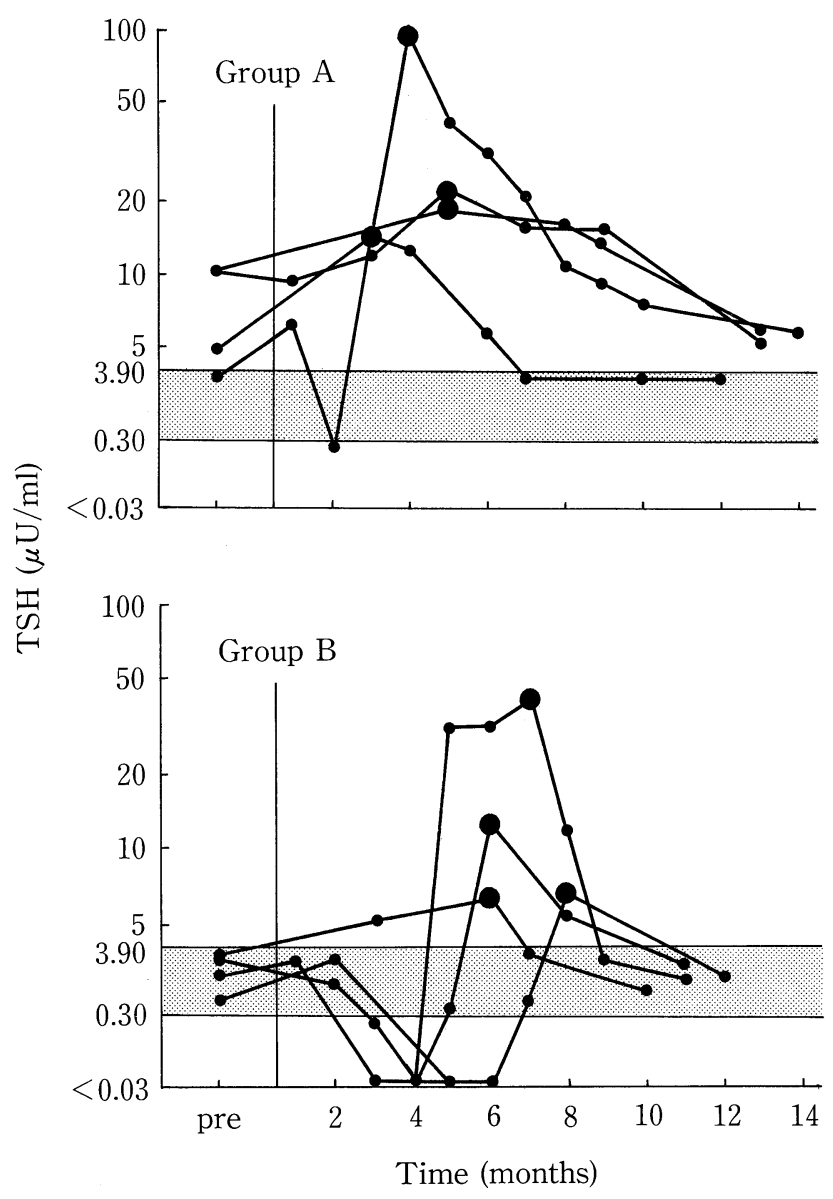

Figure 1. Alteration of TSH levels of patients with hypothyroidism or destructive thyroiditis in each group. Top: 4 patients $(1$, $4,5,10)$ in Group A. Bottom: 4 patients (B1 4) in Group B. TSH normal range $(0.30 \sim 3.90 \mu \mathrm{U} / \mathrm{ml})$. Large dots $(O)$, peak levels of TSH of each case. TSH: thyrotropin. better, but her autoantibody levels worse. Her thyroid hormone and autoantibody levels returned to the pre-treatment levels 4 months after the termination of IFN therapy. She required no replacement therapy.

\section{Patient 16}

A 53-year-old male patient was treated using the T-II protocol, but IFN $\alpha$ was reduced to 3 million units per time because of thrombocytopenia. He revealed TSH suppression $(<0.03$ $\mu \mathrm{U} / \mathrm{ml}$ ) with reciprocal $\mathrm{T}_{3}$ and $\mathrm{fT}_{4}$ elevations at the first month of IFN therapy, which remained almost constant during the 6 months of therapy and even 12 months after the completion of therapy. Thyroid $99 \mathrm{~m}$ pertechnetate uptake in this patient was normal with diffuse goiter during the 3rd and 6th month. TBII activity was slightly elevated during and after therapy: 10.9$11.0 \%$ (normal, <10\%). TSAb activity was 500\% (normal, $<150 \%$ ). This patient has been observed carefully for 18 months without receiving any antithyroid drugs. He is subjectively quite well.

In Group B, abnormal thyroid functions were observed in 4 patients during IFN therapy (10\%) [Table 4]. Patients B 1-3 exhibited TSH suppression with reciprocal elevations of $\mathrm{T}_{3}$ and $\mathrm{fT}_{4}$ levels during therapy, which were followed by elevation of TSH level and decreases in $\mathrm{T}_{3}$ and $\mathrm{fT}_{4}$ levels shortly thereafter. These patients were diagnosed as destructive thyroiditis. $\mathrm{Pa}$ tient B 1 complained of palpitation and tremor due to thyrotoxicosis. Patients B 2 and 3 did not exhibit any clinical symptoms, and IFN protocols were used without any modifications. Patient B 4 exhibited transient hypothyroidism. Each peak level of TSH is shown in Table 4 and each alteration in TSH level is shown in Fig. 1. Regarding anti-thyroid autoantibodies in Group B, only Patient B 3 exhibited a transient low titer of MCHA and TGHA. 
AMENOMORI et al

Table 4. Development of Thyroid Dysfunction in 4 Patients in Group B

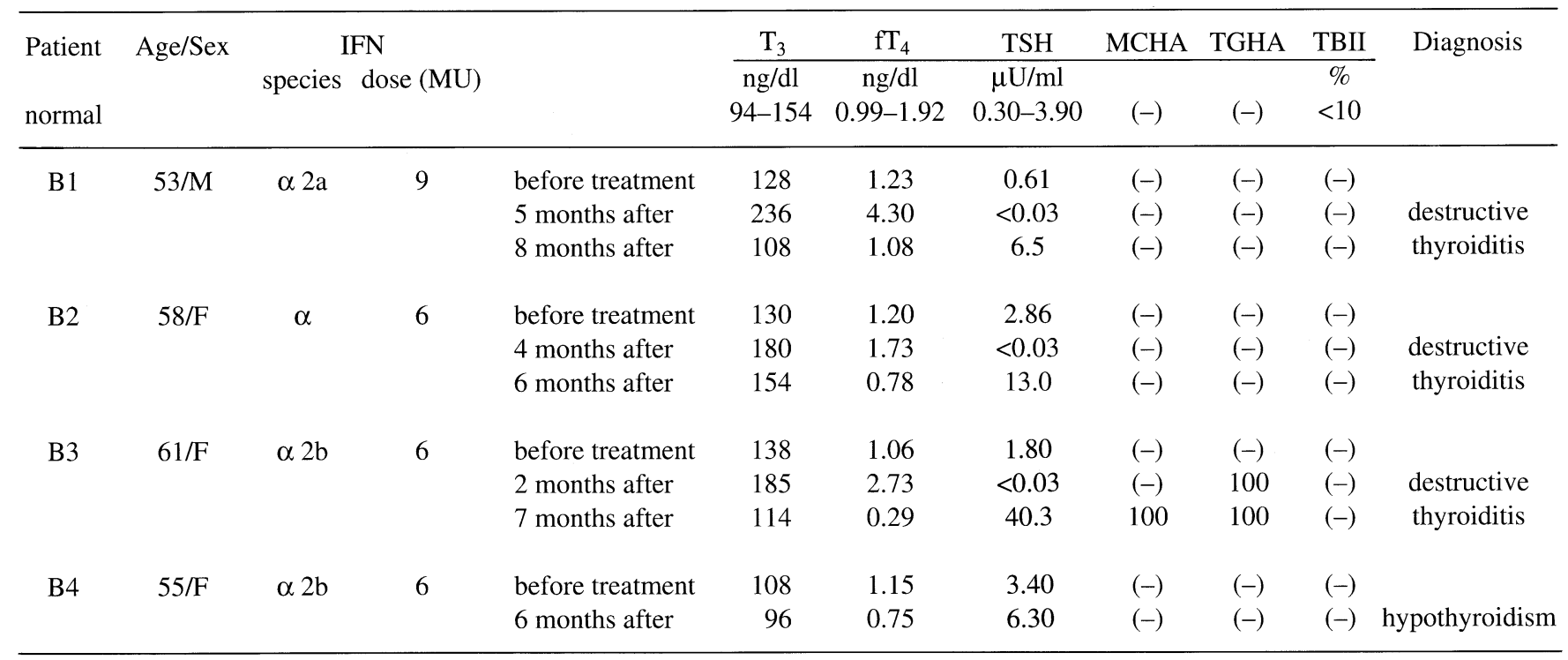

IFN: dose (MU: million units per time), $\mathrm{T}_{3}$ : triiodothyronine, $\mathrm{fT}_{4}$ : free thyroxine, $\mathrm{TSH}$ : thyrotropin, MCHA: anti-thyroid microsomal antibody, TGHA: anti-thyroglobulin antibody, TBII: thyrotropin binding inhibitor immunoglobulin.

\section{Patient B 1}

A male patient was started on recombinant IFN $\alpha 2$ a therapy at the age of 53 years. His therapy was stopped 4 months later, since he refused treatment because of general malaise and alopecia. Two weeks later he complained of palpitation and tremor which were thought to be due to hyperthyroidism. However, thyroid $99 \mathrm{~m}$ pertechnetate uptake was low at that time and returned to the normal level 2 months later. Only a $\beta$ blocker was administered for a short time. He had transient TSH elevation during the 4th month after treatment and became euthyroid during the 10th month. He was negative for all autoantibodies during and after treatment.

\section{Patient B 4}

A 55-year-old female patient was administered recombinant IFN $\alpha 2$ b. He exhibited a gradual decrease in $\mathrm{fT}_{4}$ and increase in TSH, but did not exhibit an early thyrotoxic phase. The level of $\mathrm{fT}_{4}$ was 0.93 during the $3 \mathrm{rd}$ month, and 0.91 during the 5 th month. The level of TSH was 5.0 during the $3 \mathrm{rd}$ month, 5.7 during the 5th month. During the 6th month of IFN therapy, he exhibited subclinical hypothyroidism $\left(\mathrm{fT}_{4}: 0.75\right.$, TSH: 6.3 ). His TSH level returned to normal 2 months after the 6-month protocol was complete. He was negative for all autoantibodies during and after treatment. He did not require any replacement therapy.

The alteration in TSH levels of the patients with destructive thyroiditis and hypothyroidism is illustrated in Fig. 1. In Group A, the peak TSH levels were observed relatively early (mean \pm $\mathrm{SD}, 4.3 \pm 0.8$ months), while those in Group B were observed later $(6.8 \pm 0.8)$.

Furthermore, three was no obvious relationship between these thyroid dysfunctions and either the dose or schedule of
IFN in this series (data not shown).

\section{Discussion}

This study revealed that the characteristics of IFN-induced thyroid dysfunction vary somewhat according to the thyroid state prior to the IFN therapy.

The high incidence of abnormal thyroid state prior to therapy $(32.2 \%)$ in our patients may be related to hepatitis $\mathrm{C}$ viral infection. Tran et al (12) reported a high prevalence of thyroid autoantibodies in patients with chronic hepatitis $\mathrm{C}$ before IFN therapy, although only three patients in our study were positive for thyroid autoantibodies before therapy. Even when thyroid abnormality was defined more strictly, 11 patients (18.6\%) were found to have anti-thyroid antibodies or elevated TSH levels, both of which were considered likely to be the result of an autoimmune thyroid disorder, most likely Hashimoto thyroiditis. We observed that 4 of these 11 patients developed subclinical hypothyroidism, of whom Patient 1 had low $\mathrm{fT}_{4}$ and autoantibody levels, and Patients 4, 5 and 10 exhibited TSH elevation. In Hashimoto thyroiditis such as that in Patient 1, IFN-induced thyroid dysfunction occurs usually in association with the elevation of anti-thyroid autoantibody titer, suggesting that IFN exacerbates autoimmunity in the thyroid (10). While most previous reports have focused mainly on the presence of autoantibodies, our observations revealed a high incidence of thyroid dysfunction in the TSH elevation group prior to IFN therapy. Only one of the remaining 8 patients in Group A exhibited thyroid dysfunction. This patient (Patient 16) developed hyperthyroidism during the 1 st month of IFN therapy with normal thyroid $99 \mathrm{~m}$ pertechnetate uptake and was positive for TBII and TSAb. Detection of TBII during IFN therapy has been reported (13). We also found that only 2 of our patients (Patients 
1 and 16) were positive for TBII. Patient 1 developed hypothyroidism, but we could not confirm whether her TBII positivity was due to thyroid dysfunction since her TSH-stimulation blocking antibody (TSBAb) level was not measured.

Thyroid dysfunction was induced in 4 patients out of the 40 Group B patients. Three of them exhibited early thyrotoxicosis followed by transient hypothyroidism with TSH elevations and decreases in thyroid hormone levels and were diagnosed as having destructive thyroiditis. Berris and Feinman (6) reported IFN-induced destructive thyroiditis in patients with chronic hepatitis. Furthermore, Reid et al (14) reported that, of 13 patients receiving interleukin (IL) 2 and IFN $\alpha$ combination therapy for cancer, $6(46 \%)$ exhibited cytokine-induced thyroid dysfunction, of whom 5 exhibited destructive thyroiditis. IFNinduced thyrotoxicosis without overt thyroid disease might be identified upon close examination of patients during therapy. Destructive thyroiditis consists of 2 forms: subacute thyroiditis and painless (silent) thyroiditis. Since IFN-induced destructive thyroiditis is not usually accompanied with pain, it is probably considered as the latter. However, we used the term "destructive thyroiditis" in this study because histological examination was not performed.

The mechanism of thyroid damage induced by IFN $\alpha$ and $\beta$ has not yet been clarified in detail. When thyroid dysfunction due to IFN $\alpha$ therapy was first noted, it was proposed that this might possibly be the result of IFN $\gamma$ contamination of the IFN $\alpha$ preparations used (2). However, thyroid dysfunction after administration of recombinant IFN $\alpha$ and $\beta$ was reported $(7,8)$, and we also observed that 4 patients in Group $A$ and 3 in Group B developed thyroid dysfunction induced by recombinant IFN $\alpha$ and $\beta$. It has been shown that MHC class II molecule is expressed abundantly on the thyrocytes of patients with melanoma and renal cell carcinoma who develop destructive thyroiditis during IFN $\alpha 2 \mathrm{a}$ and IL-2 therapy (15). As is well known, IFN $\gamma$ induces aberrant expression of MHC class II molecule on thyrocytes (16). Subsequently, such thyrocytes may play a role as antigen-presenting cells which activate the specific $\mathrm{T}$ cells which promote thyroid-specific autoimmune mechanisms $(17,18)$. However, thyroid dysfunction was not observed when IFN $\gamma$ was administered to patients with hepatitis (19-22). However, Daniels et al (23) reported spontaneous production of TNF $\alpha$ and IL-1 $\beta$ during IFN $\alpha$ treatment of chronic hepatitis $B$ virus infection. Gisslinger et al (24) reported serum IFN $\gamma$ level increases after the administration of IFN $\alpha$ to patients with neoplastic haematological diseases. We consider that there are two possibilities in this regard: the activation of suppressor/killer T lymphocytes which had infiltrated into the thyroid as a result of the enhancement of MHC class I molecule expression on thyrocytes by IFN $\alpha$ and $\beta$ (25) and an imbalance in the regulation of the cytokine network in vivo, for example the suppression of production of IFN $\alpha$ and $\beta$ by a feedback mechanism and/or reciprocal enhancement of the alternative production of other cytokines such as IFN $\gamma$, TNF $\alpha$ and IL-1 $\beta$.

Most dysthyroidal patients in Group A exhibited a rapid elevation of TSH level without preceding thyrotoxicosis. In contrast, most patients in Group B exhibited an early thyrotoxic phase and a significant delay in TSH elevations compared to Group A patients. Regarding the interpretation of destructive thyroiditis in relation to Hashimoto thyroiditis, many thyroidologists consider that the former should be a particular phase of the latter (26). Taniguchi et al (27) reported a case of IFN-induced hypothyroidism at a very early stage (4 days after the start of IFN therapy) in which the patient had a past history of postpartum thyroiditis. IFN $\alpha$ and $\beta$ immunologically damage thyrocytes in patients with poor thyroid reserves due to Hashimoto thyroiditis, and such damage may occur early after the initiation of therapy and may lead to the development of hypothyroidism. Thyrotoxicosis followed by hypothyroidism occurs in patients with negative or minimal thyroid damage. In these cases, thyroid reserves should be sufficient, and cell damage induced by IFN would result in the leakage of intrathyroidal hormones and subsequent thyrotoxicosis. Before the complete recovery of the thyrocytes, a transient hypothyroid phase can be frequently observed. These findings may provide new insight into the development of autoimmune thyroid disorders de novo. Together with the possibility of cytokine network disturbance, the detailed mechanism of IFNinduced thyroid dysfunction should be clarified further.

\section{References}

1) Di Bisceglie AM, Martin P, Kassianides $C$, et al. Recombinant interferon alfa therapy for chronic hepatitis C. A randomized, doubleblind, placebocontrolled trial. N Engl J Med 321: 1506, 1989.

2) Burman P, Tötterman TH, Öberg K, Karlsson FA. Thyroid autoimmunity in patients on long term therapy with leukocyte-derived interferon. J Clin Endocrinol Metab 63: 1086, 1986.

3) Fentiman IS, Balkwill FR, Thomas BS, Russell MJ, Todd I, Bottazzo GF. An autoimmune aetiology for hypothyroidism following interferon therapy for breast cancer. Eur J Cancer Clin Oncol 24: 1299, 1988.

4) Schultz M, Müller R, von zur Mühlen A, Brabant G. Induction of hyperthyroidism by interferon- $\alpha-2 b$. Lancet i: $1452,1989$.

5) Mayet WJ, Hess G, Gerken G, et al. Treatment of chronic type B hepatitis with recombinant $\alpha$-interferon induces autoantibodies not specific for autoimmune chronic hepatitis. Hepatology 10: 24, 1989.

6) Berris B, Feinman SV. Thyroid dysfunction and liver injury following alpha-interferon treatment of chronic viral hepatitis. Dig Dis Sci 36: 1657, 1991.

7) Kamikubo K, Takami R, Suwa T, et al. Case report: silent thyroiditis developed during alpha-interferon therapy. Am J Med Sci 306: 174, 1993.

8) Lisker-Melman M, Di Bisceglie AM, Usala SJ, Weintraub B, Murray LM, Hoofnagle JH. Development of thyroid disease during therapy of chronic viral hepatitis with interferon alfa. Gastroenterology 102: 2155, 1992.

9) Chung YH, Shong YK. Development of thyroid autoimmunity after administration of recombinant human interferon- $\alpha 2 b$ for chronic viral hepatitis. Am J Gastroenterol 88: 244, 1993.

10) Nagayama $Y$, Ohta $K$, Tsuruta $M$, et al. Exacerbation of thyroid autoimmunity by interferon $\alpha$ treatment in patients with chronic viral hepatitis: our studies and review of the literature. Endocr J 41: 565, 1994.

11) Kosugi $S$, Mori $T$, Imura $H$. Mechanisms by which low salt condition increases sensitivity of thyroid stimulating antibody assay. Endocrinology 125: 410, 1989.

12) Tran A, Quaranta JF, Benzaken S, et al. High prevalence of thyroid autoantibodies in a prospective series of patients with chronic hepatitis $\mathrm{C}$ before interferon therapy. Hepatology 18: 253, 1993.

13) Fonseca V, Thomas M, Dusheiko G. Thyrotropin receptor antibodies 


\section{AMENOMORI et al}

following treatment with recombinant $\alpha$-interferon in patients with hepatitis. Acta Endocrinologica (Copenh) 125: 491, 1991.

14) Reid I, Sharpe I, McDevitt J, et al. Thyroid dysfunction can predict response to immunotherapy with interleukin- 2 and interferon- $2 \alpha$. Br J Cancer 64: 915, 1991.

15) Pichert G, Jost LM, Zöbeli L, Odermatt B, Pedio G, Stahel RA. Thyroiditis after treatment with interleukin-2 and interferon $\alpha-2 \mathrm{a}$. Br J Cancer 62: 100, 1990.

16) Todd I, Pujol-Borrell R, Hammond LJ, Bottazzo GF, Feldmann M. Interferon- $\gamma$ induces HLA-DR expression by thyroid epithelium. Clin Exp Immunol 61: 265, 1985.

17) Rhodes J, Jones DH, Bleehen NM. Increased expression of human monocyte HLA-DR antigens and $\mathrm{Fc} \gamma$ receptors in response to human interferon in vivo. Clin Exp Immunol 53: 739, 1983.

18) Bottazo GF, Pujol-Borrell R, Hanafusa T. Role of aberrant HLA-DR expression and antigen presentation in induction of endocrine autoimmunity. Lancet ii: 1115, 1983.

19) Kung AWC, Jones BM, Lai CL. Effects of interferon- $\gamma$ therapy on thyroid function, T-lymphocyte subpopulations and induction of autoantibodies. J Clin Endocrinol Metab 71: 1230, 1990.

20) Sáez-Royuela F, Porres JC, Moreno A, et al. High doses of recombinant $\alpha$-interferon or $\gamma$-interferon for chronic hepatitis C: a randomized, controlled trial. Hepatology 13: 327, 1991.
21) Ruiz-Moreno M, Rúa MJ, Moraleda G, Guardia L, Moreno A, Carreño V. Treatment with interferon gamma versus interferons alfa and gamma in children with chronic hepatitis B. Pediatrics 90: 254, 1992.

22) Weber P, Wiedmann KH, Klein R, Walter E, Blum HE, Berg PA. Induction of autoimmune phenomena in patients with chronic hepatitis $\mathrm{B}$ treated with gamma-interferon. J Hepatol 20: 321, 1994.

23) Daniels HM, Meager A, Eddleston ALW, Alexander GJM, Williams R. Spontaneous production of tumour necrosis factor $\alpha$ and interleukin- $1 \beta$ during interferon- $\alpha$ treatment of chronic HBV infection. Lancet 335: 875, 1990.

24) Gisslinger H, Gilly B, Woloszczuk W, et al. Thyroid autoimmunity and hypothyroidism during long-term treatment with recombinant interferonalpha. Clin Exp Immunol 90: 363, 1992.

25) Trinchieri G, Santoli D, Koprowski H. Spontaneous cell-mediated cytotoxicity in humans: role of interferon and immunoglobulins. J Immunol 120: $1849,1978$.

26) Volpé R, Amino N. Round table discussion on "Concepts of Hashimoto disease". in: Nagataki S, Mori T, Torizuka K, Eds. 80 years of Hashimoto Disease. Excerpta Medica, Amsterdam, 1993, p. 553.

27) Taniguchi $Y$, Murakami $T$, Nakanishi $K$, et al. Two cases of hypothyroidism associated with alpha-interferon therapy. Intern Med 31: 373, 1992. 